\title{
Stories that Move. Fiction, Imagination, Tourism
}

\begin{abstract}
The subject of this article is media tourism: the phenomenon of people travelling to places which they associate with novels, films or television series. Existing knowledge about this phenomenon is fragmented, and principally based on individual case studies of eye-catching examples. This article aims to go beyond the limited scope of case studies and to explore an underlying, more generic process. It investigates which stories are remembered by individuals and under what circumstances people decide whether or not to go travelling to the places associated with these stories. Based on a series of in-depth interviews, the article concludes that every human being has a small treasure trove of stories which they love and which are considered part of their identity. The interviews suggest that there is a strong relationship between the recollection of beloved stories and tourist practices - both in terms of destination decision making and tourist experience.
\end{abstract}

\section{Key words}

Film

Television

Literature

Fiction

Place

Identity

Reijnders, S. (2015). Stories that move. Fiction, imagination, tourism. European Journal of Cultural Studies. Published online before print August 18, 2015, doi:

$10.1177 / 1367549415597922$. 


\section{Stories that Move. Fiction, Imagination, Tourism}

\section{Introduction}

More and more people are travelling to destinations that they know from popular novels, films or television series. One example would be the stream of tourists to New Zealand following the release of the movie adaptations of The Lord of the Rings. It has been estimated that after this trilogy hit the cinema, the amount of international visitors to New Zealand more than doubled, resulting in an enormous boost to the second largest economic sector of the country (Roesch 2009: 9). The emergence of this particular form of niche tourism has not gone unnoticed in academic circles. Under headings like 'film-induced tourism' (Beeton, 2005), 'cinematic tourism' (Tzanelli, 2004) and 'media tourism' (Reijnders, 2011) systematic investigation of this phenomenon has been conducted since the start of this millennium, with a couple of noticeable forerunners in the 1980s and 1990s, such as Cohen (1986), Butler (1990), Riley \& Van Doren (1992) and Riley, Baker \& Van Doren (1998).

The majority of this research is based on case studies: empirical analyses of specific eyecatching examples of media tourism. It is noticeable that many studies have been based on an analysis of The Lord of the Rings. A drawback of this is that it is sometimes difficult to determine to what extent the results can be applied more generally. Theory in this field of research is therefore less developed than might be hoped (Connell, 2012: 1012-1013, 1025). More remarkably, it can be said that the profusion of case studies has led to a one-sided, retrospective vision. Some attention has been paid to examples of media tourism that have been successful, though little is known about why other novels or films have not led to tourism. In addition tourists are normally asked afterwards (or during their holidays) why they have visited a particular site and how they have experienced this visit. What we know little about is the phase before that: the period in which they are considering whether or not to visit a particular location from a story that they love.

By focusing on this preceding phase, research into media tourism can be placed in a wider context. After all the phenomenon of media tourism is not limited to the actual act of tourism, but is embedded in a longer process of the imagination, which stretches out over time, a process that begins with the consumption of the media narrative and fantasizing about the 'fictitious' locations concerned and ends with a look back on the experience (Urry \& Larsen 2011; Connell, 2012, p. 1024; Lean, Staiff \& Waterton, 2014). Novels, television series and films create elaborate imaginary worlds. These worlds are reproduced in the imagination of the readers/viewers while they are reading/watching. In many cases, the readers/viewers identify with one or more of the characters in the story and in their minds transport themselves into and through this imaginary world. When the 
media tourist finally makes his/her journey, this trip more or less represents a realization of an earlier imaginary journey (cf. Laing \& Crouch, 2009; Ehn \& Löfgren, 2010, p. 142; Adams, 2014).

This article makes further inroads into the imaginative processes that precede an act of media tourism. Care is taken to go beyond the specificities of individual case studies and to make a contribution to more general theory. To achieve this, this article does not use a specific film or novel as its starting point, but a generic process, which precedes an actual act of tourism: daydreaming about 'fictitious' locations from films or novels and (re-)imagining the related locations. This article does not so much interest itself in the specific, practical travel arrangements made by media tourists. It is primarily concerned with the phase before that: how, when and why, in the context of their daily lives, do people fantasize over diegetic worlds and under what circumstances do they decide whether or not to take a trip to the related locations.

Since existing academic literature offers no answer to this question, we have decided to conduct an exploratory study. With this aim in mind, in-depth interviews have been conducted with fifteen respondents. These interviews went deeper into the individual imaginary worlds of the respondents and examined the role of the stories in them. Before the results of these interviews can be presented, however, a theoretical foundation of the concept 'imagination' must first be laid.

\section{Imagining Fictional Worlds}

In 1984, the American anthropologist John Caughey wrote an elaborate book about the role and meaning of the imagination in present-day American society. In Imaginary Social Worlds, Caughey suggests that people live in two different worlds simultaneously. On the one hand they live within a reality perceptible to the senses, contained within time and physical space. By means of sight, smell, touch, taste and hearing, they create an impression of their immediate surroundings. On the other hand, they move in a spiritual world built on memories, visions of the future, fantasies, daydreams and stories which play out elsewhere - in a different time or place, a world that thrives by virtue of the imagination.

What Caughey goes on to assert is that this world of the imagination is not an individual matter, but has largely a social character. Fantasies, daydreams, visions of the future and memories are normally about our relationships (whether real or not) with other people. Our imaginative world is populated by people - either people we know from our immediate environment or celebrities whom we have become acquainted with via the media. Almost no dream, fantasy or memory is protected from the appearance of our peers.

At a more fundamental level it may be argued that the whole fabric of our imagination is shaped by a socio-cultural context. It is culture that provides the building blocks for the composition of the fantasies and dreams that populate our inner beings. Instinctive, organic emotions such as 
fear, love, hate and lust will also excite the imagination, but then it is the schemata of our culture that determine how these emotions take shape and result in certain scenarios, roles and locations.

What we assume in this article is that stories play an essential role in this process. Stories are crucial to the way we interpret the world around us and provide meaning for us. Some cultural scientists have even claimed that man is not in fact homo sapiens (the thinking man), but homo narrans: a creature that likes to tell and hear stories, in order to provide meaning for the chaos that surrounds him (Berger, 1997: 174). Narratives give order to reality: they make a causal connection between events, creating the appearance of stable identities and - last but not least - give shape and colour to our imagination (Gottschall, 2013).

All these stories, from the media and beyond, together create a rich associative imagination of the world. For many people, television, film and other forms of popular culture act as a depot for the imagination or, in the words of André Malraux , a 'musée imaginaire' (Malraux, 1967, quoted in Lukinbeal \& Fletchall, 2014, p. 225). According to the American anthropologist Arjun Appadurai (1996), globalization has brought momentum to this development. In a world of intercontinental migration and free movement of people and goods, according to Appadurai, it is the well-known stories from movies and TV shows that still provide something to hang on to for world citizens far from 'home'.

How do these associations between story and place come about? If we define stories as a causal concatenation of meaningful events (Ball, 1994, p. 5 \& 43), and events in turn as 'something that happens', then it follows that stories always literally take place somewhere. Stories do not occur in a vacuum, but in particular areas, whether these are identifiable or not. The areas in which the story takes place are not randomly chosen as a rule, but serve to support the narrative. They create an atmosphere in which certain fictitious transactions may take place which are credible to the reader/viewer. In other words, the narrative space plays a supporting role in almost all stories. This leads to a situation in which sites that are known for the stories that take place in them, may be symbolically associated at a later stage with the plot and moral themes of the story concerned. There is also a certain reciprocity here: locations are chosen because they fit well with the story, but at the same time these stories reaffirm and empower the associations that the location inspires, creating powerful 'imaginative geographies' (Urry \& Larsen, 2011).

These associations between story and place can go in two directions. On the one hand, stories can contribute to a positive evaluation of certain sites where the relevant (urban) landscape is associated with positive values such as security, nostalgia, happiness, freedom and safety. Thus, a form of topophilia (Tuan, 1974) may occur: the love of a place, which in this case arises from the love of a story that takes place there. Certain landscapes seem particularly well suited to stimulating the imagination in this way. In this regard Ehn and Löfgren use the term 'dreamscapes': these are specific 
landscapes, such as the desert, the hills, the woods or the beach, which because of their distinct physical characteristics can easily serve as carriers of meaning (Ehn \& Löfgren, 2010, p. 157-160). Comparable is the term 'symbolic environment' in the work of Donald Meinig (1979, cited in Riley, 1992). An example of such a dreamscape would be the mountains of New Zealand, that have set the scene for several mythical narratives, ranging from Samuel Butler's Utopian society of Erewhon, published in 1872, up to the more recent The Lord of the Rings trilogy (Buchmann, 2006; Jones \& Smith, 2005).

Equally, stories can lead to forms of topophobia: fear of a place. Popular culture has a colorful mix of narrative genres in which horrific, frightening or dramatic events take place, ranging from classical genres like the ghost story or the murder song to more contemporary (media) genres such as the thriller or horror story. These stories are usually played out in recognizable, topographically identifiable locations, but at the same time concern locations that can be traced back to certain archetypes that we, developing the themes of Ehn and Löfgren, could label as 'fearscapes'. Examples of these might include abandoned houses, remote hamlets, basements and forests, wild and deep seas or dilapidated neighbourhoods. The imagination can recognize many of these dark points of reference where evil seems to have nested.

Related but not identical to the dichotomy between topophilia and topophobia is the contrast between the 'Self' and the 'Other'. According to cultural sociology, these two categories are the basis of how individuals and groups categorize the social reality around them. People are constantly trying to highlight their own identity vis-a-vis an imaginary 'Other' (Goffman, 1959). This cultural categorization also has a spatial counterpart: certain locations are considered by individuals or groups as their own territory (the home, the office, the place they were born, the homeland, the place where they live), while other locations are considered as the territory of the 'Other' (the city of a rival football team, a neighbouring country, another continent).

Territories of the 'Self' usually have explicitly positive connotations: these are related to safety and security, to the Heimat and the roots of people's own identity. While territories of the 'Self' are often appreciated, territories of the 'Other' frequently coincide with forms of topophobia. However, there is, of course, in this regard no iron law. In practice, many different variations are conceivable, for example, when the 'Other' is associated with positive values and the distant, unknown land has an exotic if not mysterious pulling power (e.g. Laing \& Crouch, 2009). In those cases, the 'Other' is not home to the danger of attack, but quite the opposite: it represents the promise of transformation or transgression - a desirable adaptation of what is considered as the current 'Self'.

In summary, this section states that every person has an imagination - an imaginary construction of the universe surrounding us - and that popular stories in the media provide the 
building blocks for this. Stories inject the imagined landscape with meaningful, emotional associations, either positive or negative, and mark the 'Self' and the 'Other' symbolically in this imagined space. What we presuppose is that these associations are at the root of the phenomenon of media tourism. Based on the processes of topophilia/topophobia presented in popular stories, and identification with these, people may take the decision to make a journey and thus come closer to the locations which they admire or despise. To see to what extent the assumptions posited in this section have been founded and developed in reality, empirical research is needed into the concrete practice of imagination in individual readers/viewers.

\section{Methods}

When investigating the experience of media tourism, it is not unusual as an 'embedded' researcher to participate in the experience and to interview other media tourists during or after the trip (e.g. Roesch, 2009; Reijnders, 2011). However, a different approach had to be selected for this article. At the core is the decision-making phase in media tourism: the period between the consumption of the media narrative and the possible (but not essential) journey that follows it. In theory it is possible to ask media tourists questions about this decision-making phase after the event. However, here are two problems that could be anticipated with this approach. Firstly, the experiences of the journey may cloud any memories of the decision-making phase, with this then being too greatly evaluated in the light of the journey that followed it. Secondly conducting the interviews afterwards leads to a situation in which only 'successful' stories are involved in the analysis given. To avoid these pitfalls, the choice was made to interview a selection of respondents, for whom it was unclear in advance if they were active media tourists or if they planned to be in the near future.

This approach however brought with it one disadvantage. In the usual combination of interviews and participant observation there arises naturally a certain level of trust between interviewer and respondent. After all, they have participated in the same activity. Such a basis of trust is of great value for the depth of the interview: the respondent should feel free to share any thoughts and feelings that arise during the interview. But this advantage is absent in situations in which people are approached randomly, for example on the street, for an interview.

To overcome this potential problem, the choice was made for this article only to interview acquaintances, friends, family and colleagues for whom it could be assumed that there existed a sufficient basis of trust to conduct an in-depth interview. Naturally this choice then had a strong influence on the data. For a start, all the respondents came from the Netherlands and especially from places with which the researcher has a strong connection: Amsterdam, Haarlem, Rotterdam and Texel. Secondly, the majority of respondents were highly educated, middle-aged white people. In principle, it is not a problem that the respondent group has a distinct profile, but we will have to 
include the socio-cultural background of our respondents explicitly in the analysis. Individual imaginative worlds are highly influenced by socio-cultural context (Ehn \& Löfgren, 2010, p. 177-187).

A total of fifteen semi-structured in-depth interviews were conducted (Bryman, 2004, p. 314323), with ten men and five women in an age range from 21 to 70 years old. An attempt was made to conduct all the interviews in a quiet, familiar environment with few visual or audible stimuli with dimmed lighting and where the respondent was invited to sit on a sofa or in an armchair. Earlier studies have suggested that the dimmed lighting and comfortable seating arrangements are conducive to the stimulation of the imagination (Ehn \& Löfgren, 2010, p. 138-139 \& 162-169). This knowledge was consciously adapted for the current project.

The interviews were set up in a semi-structured manner. Questions were determined in advance, but the list was not followed in any strict fashion. The respondents were given the opportunity to introduce their own subjects and perspectives, as long as these had some relevance to the central topic. The interviews with tourists were structured along four parts: beloved stories; role and importance of diegetic spaces in the recollection of those beloved stories; connection to personal life history; connection to existing geographies and (potentially) to media tourism. Each interview has been transcribed word for word (Bryman, 2004: p. 314-323). These transcripts were thoroughly compared. First, similarities were sought, as these could indicate general, common structures. Then, special attention was paid to striking differences and exceptions to the rule, keeping our eyes open for the diversity and inner dynamics of the phenomenon of media tourism (e.g. Reijnders, 2011).

\section{Analysis}

A small painting hangs in the kitchen of Majella. You have to stand right in front of it in order to work out what is in the picture. It is an impressionistic, dreamy image of a country house, surrounded by trees. Majella bought the painting in a gallery in England. Yet she does not associate the painting with this particular trip. For her, this painting represents something else. The estate in this picture reminds her of a book she read in her youth and which has never left her since then: the novel, Le Grand Meaulnes by Alain-Fournier. This standard of French, early modern literature, tells the story of seventeen-year-old Augustin Meaulnes, who, during a nocturnal, mysterious party at an estate in the French countryside, meets the love of his life. Le Grand Meaulnes belongs to a small group of stories for Majella, which are close to her heart and which she thinks about with some regularity, for example during quiet moments in her day, while sitting in her kitchen.

Majella is not alone in this. All the respondents who were interviewed for this project have a small treasure trove of 'beloved stories': novels films or stories that have been told to them, which they talk about with affection. Sometimes these might be novels or films, which they read or saw in 
their youth and which they strongly associate with their youth and the time period associated with it. Other cases involve novels, films or television series from more recent years.

It is not the case that these stories are recalled on a daily basis or constitute an active part of the respondent's life. Quite the opposite, in many cases the respondents experience some difficulty in dredging the complete story from their memory. Often the titles are missing or the names of authors or directors have been forgotten. But even though these stories may have been partly forgotten in the mists of time, they are still considered by the respondents as valuable.

\section{Place}

So what is the role of the place in the remembrance of these beloved stories? To start with, this role should be immediately put into some sort of perspective. When respondents talk about beloved stories, initially it is often the characters and plots that are described. The diegetic space - the universe constructed within the narrative in which the plot unfolds - is only part of the memory. It is, however, quite an important part. It is striking, for example, that all beloved stories are in any event localized. Respondents described how they could form an image of the spaces and landscapes that are described in the story. These areas or landscapes also tend to relate to specific geographical regions or places. Often the geographical positioning corresponds to the original intention of the writer or director. In other cases, the geographical designation is changed or added by the reader/viewer. So the respondent Floris tells of how he correlates a castle from the story Geheimen van het Wilde Woud [Secrets of the Wild Forest] by Tonke Dragt to an existing castle in the Dutch province of North Brabant:

I like reading stories. [...] That's because they have descriptions in them and I mull over these descriptions in my head and then I get a picture of a place that I have already been to instead of sticking closely to the description. So in a story with a castle and a dining room, I think of the dining room at Loevestein, which then becomes the dining room in the story. And the drawbridge in the story, that's the drawbridge at Loevestein.

- Floris (Rotterdam, 31 years old, teacher

What Floris does is fill in the diegetic space based on memories of places he has been to himself. The story is, as it were, linked to the geographical reality, in spite of the generic, placeless character peculiar to many children's novels.

That the location of the story is an important part of the memory of beloved stories, is further demonstrated by the fact that in some cases it is only the space that can still be remembered. This is what Anna says about her memories of exactly the same book, Geheimen van het Wilde Woud: 
It is very dark with large trees, very dark so difficult to see properly. Lots of leaves. It's actually very frightening. I can't remember what the book is about any more but that image of the forest is kind of unpleasant in my mind. [...] Dark and impassable. Big trees. But also a sort of.... d don't know, also kind of safe, because the main characters in the story felt at home in that forest.

- Anna (Amsterdam, 37 years old, publicist)

It is the forest that Anna still can remember, and not the stories that are played out in that forest. That the location of action comes so much to the fore, may be partly explained by the specific characteristics of this novel: as the title implies, the setting in Geheimen van het Wilde Woud is more than just a backdrop. It is a factor that helps to determine the development of the plot. Yet a similar theme returns in the discussion of other novels and films: the location of the action represents in almost all cases a by no means negligible role in the recollection of beloved stories.

What is now striking is that during the interviews certain 'archetypal' sites recur repeatedly for every respondent: places reduced to abstract, non-localized basic forms, such as 'the forest', 'the lake', 'the village', 'the rolling countryside', 'the hills', but also more demarcated areas such as 'the house' or 'the outskirts of the village'. This seems to correspond to the concepts of 'dreamscapes' (Ehn \& Löfgren, 2010) and 'symbolic environments' (Meinig, 1979) discussed previously. However, it should be noted that the landscapes described by the respondents were not always experienced as positive. For example, a lot of the stories that Anna can remember play out in forests, while Anna herself expressed the sentiment that she 'really hates' forests.

That the memories of beloved stories are centred for each respondent around specific symbolic environments is a remarkable result. The interviews had not been set up to achieve that. The conversations began, as previously described, with a broad, general listing of popular novels and films. Only then did the discussion move on to the question of what landscapes, environments or specific areas in these novels and movies play a role. Despite this broad, general approach, almost every interview gradually drifted towards a particular type of landscape or place. Thus all the beloved stories of the respondent Manuel took place largely in a village. It didn't matter whether they were the novels of Hugo Claus or the children's books De Kleine Kapitein [The Little Captain] or The Never Ending Story: all these stories were connected in Manuel's memory to a similar environment, a quiet village community, where life seems to stand still and all the people know each other. Similarly, the beloved stories of respondent Eva took place mostly in or around a (family) house, with books like The Little House on the Prairie, The Diary of Anne Frank, Noorderzon [Northern Sun], and Perpetuum Mobile [Perpetual Motion], and films or TV series like La Meglio Gioventù [The Best of Youth], The House of Eliott and Homeland.

It is important to underline that these findings are not primarily related to factual, textual features in the stories concerned. For example, it is questionable whether in terms of content the 
houses really play a major role in the TV series Homeland. It could be argued that the headquarters of the $\mathrm{ClA}$ is at least as important a setting. In the memory of Eva, however, it is mainly the domestic scenes from Homeland that have stuck, like the scenes in the home of the main character Carrie Mathison and the scenes in the cabin where Mathison and her counterpart Nicholas Brody spend two weekends. The structures found so far do not indicate much in terms of textual patterns in literature and film, but rather in the way in which these media are interpreted and remembered - in processes that take place within the perception of the respondents.

These processes do not take place with the full awareness of the respondent. Thinking about beloved stories and their locations seems rather to be a semi-conscious process that takes place at unexpected, occasional moments in everyday life. Sometimes these thoughts are triggered by external stimuli, such as the smell of a certain scent or the sight of an object that is reminiscent of a beloved story. So tells Eva:

\begin{abstract}
We were in Venice at the time. There is that famous bridge there, the one which goes over the water and all the houses are built on it. We went inside one such building and there was a Jeweler or something I think...That was when I really thought: This is the place where the man in Das Parfum [Perfume: the Story of a Murderer] went in, even though that was set in Paris [...] The place seemed so much richer with more colour [...] You can also smell the place.....and also er... hear the voices and get the feeling that you are really in the middle of the novel.
\end{abstract}

- Eva (Haarlem, 34 years old, museum education officer)

There also occur in everyday life, certain situations in which, without the intervention of external triggers, thoughts wander to beloved stories and the sites associated with them. For example, respondents relate how during calm moments - lying on the couch or sitting in a lounge chair - they like to think about various matters, and in doing so, their thoughts do not proceed in a rational, logical way, but make more of an associative link with each other like a string of beads. These thoughts can go in any direction, including that of popular stories. However, it is worth noting that this is by no means an everyday practice.

Daydreaming about fictional locations is irregular and is also generally of short duration, because other impressions or thoughts command the attention and distort the image. The interview situation is in that sense an artificial and exceptional situation. The thoughts about the beloved stories are in fact recalled in full awareness during interviews and then maintained for over an hour in a quiet, dimly-lit room without any distractions. It is therefore not surprising that for many of the respondents the interview sets in motion a certain awareness. The discovery of the symbolic environment in particular is experienced by most respondents as a sort of eureka moment, as something they 'suddenly think of' (Manuel) or that they realize for the first time with amazement: 
This is what came to my mind when I just told you. [...] I start to realize a kind of pattern in these novels. I really never knew that there is a kind of spatial pattern in these novels...

- Milan (Amsterdam, 33 years old, Ph.D. student)

\section{Meaning}

Asked for an explanation of why it is this kind of place that recurs in remembering their beloved stories, about half the number of respondents noted that the landscapes observed are very similar to those of their own childhood environment. As Milan says:

\footnotetext{
Well, I think that the school [from School at the Border] really reminds me in my imagination to my primary school, which is kind of rigid and cold, with big spaces.
}

- Milan (Amsterdam, 33 years old, Ph.D. student)

When asked what places he remembers from The Never Ending Story, Manuel says that he must, in particular think of the school of Sebastian, the main character, but he also makes explicit the link to his own school. Similarly, in his imagination the story of Reynard the Fox is situated in the Geysterse woods in his home town of Venray. A similar phenomenon seems to occur with Milan and Manuel as was observed previously with Floris: stories are not consumed passively but actively appropriated in that narrative spaces are filled in and coloured in on the basis of personal experiences in their own environment.

This relationship between beloved stories and childhood environment is complex and mutual. In some cases, stories are, for example, actively used to appropriate their own environment and make it more 'enchanting' and exciting. Thus Bernard reports that he and his friends were fans of Arendsoog [Eagle Eye], and that they recreated the world of Arendsoog in the sand dunes outside their village: their childhood games were modelled on the adventures of the cowboy Arendsoog and his Native American friend Witte Veder [White Feather], and the dunes served as American prairies.

What can be tentatively concluded on the basis of the remarks of Manuel, Milan, Floris and Bernard is that narrative spaces that resonate with an individual's own childhood surroundings have a good chance of being recalled later in life. Within the group of respondents surveyed this occurs particularly in books, especially in children's literature (cf. Laing \& Crouch, 2009). However, during the interviews symbolic environments will also come up that are not explicitly related to the environment of the respondents' youth, but are actually far removed from their own environment. As Jan says:

When we went hiking in the mountains of Switzerland a few years ago for the first time, I had to think of the books of Hesse [...] Because Hesse always describes a sweltering heat with only buzzing bees and bumblebees around. And when you experience that, that something suddenly just comes up, that it just pops into your head, 
then you think: this is a real Hesse moment [...] You feel kind of close to Hesse. [...] That's why I like going to the mountains. To get that perfect image again [...]

- Jan (Haarlem, 54 years old, social worker)

For Jan the hillside is a recurring ideal type. He contrasts the hills with the 'flat polder' where he grew up, but sees it at the same time as an idyllic model - a natural, harmonious and pastoral world which he wants to identify with. Again therefore processes of identification play a strong role, albeit in a different way than in the previous examples. Within the prior theoretical framework, this was designated as the idealization of the 'other'. The interview with Jasper was comparable. In many of his memories of beloved stories like Twin Peaks, Olivier B. Bommel [Oliver B. Bumble] and the work of Murakami, the same environment returns: a largely deserted, hilly landscape surrounded by mist and a single, deserted house. This is not the place where he himself comes from. So why is that landscape still immersed in his memory?

It is really special when there is nothing there. And you are aware of that. Then you think to yourself. Gosh, all alone in the world. [..] That feeling of being completely alone in the world. It doesn't get any more special than that. [...] That can be beautiful, but it may also be a little sad that no one else can see this. [...]I'm a bit of a maverick, primarily concerned with things I'm doing on my own.

- Jasper (Den Burg, 39 years old, businessman)

Jasper recognizes in the deserted landscape his own desire for solitude. The interview with Milan reveals an even more explicit relationship between a specific symbolic environment - the house on the outskirts of the village - and the picture that the respondent has of his own identity:

It is always about moving between outside and inside: the edge of the village and the centre of the village. [...] I think it's more like the general state of my being. I never really... I always felt a little bit of being an outsider or observing the things from a kind of perspective.

- Milan (Amsterdam, 33 years old, Ph.D. student)

The environments described by Jan, Jasper and Milan have a strong symbolic significance. They symbolize how these three respondents perceive part of their own identities. In a metaphorical sense, these could be described as 'soulscapes': symbolic environments which individuals identify themselves with, and where, in a lost moment, the soul wanders around happily.

\section{Media tourism}

As some previous quotes have already shown, the subject of tourism crops up almost automatically in the interviews, without being explicitly asked. There seems to be a strong, mutual relationship 
between tourism and beloved stories. For many respondents the holidays are a normal time for reading books. Frequently books are taken on holiday for the explicit reason that their action occurs in the place of the holiday destination. Other respondents read books not in situ, but prior to the trip, as a literary exploration of the destination.

Conversely holiday locations are often chosen because of their association with a beloved novel, television show or movie. When asked during the interviews whether there are specific locations of beloved stories that they would like to visit, more than half of the respondents answered positively. In this sense there may be, at least in the group studied, a latent need for media tourism. According to Laing and Crouch (2009), books are the most powerful 'image formation agents'. This turned out not to be the case in the current study: movies and TV series were just as important.

The desire to visit locations related to popular narratives was motivated in different ways. As has been noticed before in media tourism research, reasons for engaging with these kinds of experiences differ strongly (Connell, 2012, p. 1016; Macionis, 2004). In this case, a total of four partially overlapping patterns can be observed. Firstly, some of the respondents consider visiting locations from beloved stories as a way to step into the shoes of the characters and experience the same feelings as them. As Manuel relates:

\footnotetext{
I think about the apartment in The Stranger somewhere in the city of Paris in France. [...]The novel is about a certain calming idea which takes effect while the figure is sitting there with a drink and a book, as he looks out over his balcony and the city as it goes about its business. That uh ... I'm curious about whether I would experience it like that.
}

- Manuel (Utrecht, 37 years old, graphic designer)

Milan also articulated the desire to get under the skin of the characters and become part of the story:

\begin{abstract}
This summer when I read this Israeli novel [about hiking in Israel], I decided that this year, at least for a week, I want to go to Israel and at least for a couple of days I want to go hiking [the same national trail]. It is because of the story of the protagonists. I can really relate to the protagonists in a sense that one of the protagonists is very much someone who reminds me of myself, another one is more like someone who I would like to be. [...] It is a recurring fantasy for me, that I wish I would be part...
\end{abstract}

- Milan (Amsterdam, 33 years old, Ph.D. Student)

Manuel and Milan seem to feel the need for some form of metempsychosis: to transmigrate into another - in this case fictional - individual, to see the world through their eyes and experience the same feelings (cf. Seaton, 2002). In a sense, this desire can be seen as an extension of the original 
reading or viewing experience, by which people identify with and project themselves into a character (cf., Frost, 2010; Kim, 2012; Laing \& Crouch, 2009, p. 193-194).

For other respondents, it is not so much about the characters and evoking or even joining the diegetic world, as much as following in the footsteps of the creators, understanding the creative process that the writers or directors have undergone and negotiating the resulting difference between the diegetic and the real (cf. Torchin, 2002). As Anna says:

I think it is a kind of tribute. [...] It is a sort of fan association. And then, to pay your respects to the place, right? It is that sort of feeling. Like, I owe it to myself or to the creators to take a long look at this location that was here. That is here. [To see] what the author has done to make it more beautiful or to emphasize something perhaps.

- Anna (Amsterdam, 37 years old, publicist)

The third pattern that was observed during the interviews relates to the underlying values of the story. Niels mentions for example that he has a lot of appreciation for the world that is the setting for the stories about Pippi Longstocking. A visit to Villa Villekulla in southern Sweden could therefore offer him a special experience.

It is good to use your imagination. [...]To have an open mind and try to make discoveries. That place [Villa Villekulla] I associate with the character of Pippi Longstocking, who is also very much in pursuit of her fantasy world. [...] That's why I wouldn't mind going to this place. Because at any rate I wish I could do things in that way, too. [...]It's more the way of thinking that I strive after, that I could find most at that particular location.

- Niels (Rotterdam, 30 years old, Ph.D. Student)

For Niels, Villa Villekulla is a place where certain values are enshrined; general values that transcend this particular story. By traveling to this place his commitment to 'a certain way of thinking' may be perpetuated or even energized. There seems to be a parallel with earlier research into male James Bond tourists for whom visiting James Bond locations was a way to strengthen symbolically their own masculinity (Reijnders, 2011). Similarly, Macionis (2004) identified ego-enhancement and selfrealization as two important motivations of 'specific film tourists'.

Finally, several respondents talk about the game element inherent in media tourism. Visiting the locations of beloved stories may provide a platform for them to stimulate their own memory and imagination and give free rein to them (cf. Buchmann, Moore \& Fisher, 2010). Part of this game is to take part in re-enactments: reenactments of episodes from a story. 
The importance of re-enacting has been observed before (e.g. Kim 2010), but emphasized in the current study are the social qualities of these re-enactments. These are usually not solitary activities. For most people, they are undertaken socially. Re-enactments are a way to share the love and knowledge of a particular story with like-minded people. Floris relates that he goes on holiday every year with a group of friends, with whom he shares a love of certain stories:

Normally we might visit a castle. [...] and then you really have to shout in a group: 'The enemy are coming!', you know? Or we might be in Normandy and then you really have to do something about....then someone has to quote from The Longest Day. [...] Then someone does the same thing and then everyone knows what is happening. [...] It is like playing, sharing something together, share a sort of perception. [...] It also confirms your friendship.

- Floris (Rotterdam, 31 years old, lecturer)

By working together to perform re-enactments, not only is the love of certain stories shared. At the same time it is a way to reaffirm mutual friendships.

However, not all respondents wish to visit a particular location in a popular story. For Eva for example, the association may not be too emphatically prominent and works more powerfully when the association occurs casually and spontaneously:

I'm not a media tourist, I don't do that, I think it's too contrived. I think it's better if I just walk through a landscape, and the association comes simply from within myself, from lots of small nuances, rather than expressly travelling to a place and feeling obliged to draw all the comparisons.

- Eva (Haarlem, 34 years old, museum education officer)

Pieter (Den Burg, 70 years old, retired) also indicates that he thinks it is important that the imagination is given room and is not pinned down to a specific location. He prefers a more general, parallel atmosphere at a given environment, without there being explicit 'markers'.

Finally, there are some respondents who rebel outright against the idea of visiting locations from popular stories. They argue that some locations, such as the New Jersey of The Sopranos, are simply not interesting enough to visit. But there is a little more to it than that:

To be honest I find it all a little hysterical. [...] I would actually find it a little embarrassing to...let's say, take such a trip. Put it this way, I don't really feel the need to do that. [...] I might even look down a bit on that sort of tourism. 
Pejorative terms like 'embarrassing' and 'hysterical' do not just fall from the sky, but echo a widespread discourse within wider society. In that respect media tourism not only provides a number of opportunities, it also brings with it a number of risks. Media tourists find themselves, as it were, on thin ice. They run the risk of getting stuck with two rather negative labels: that of the avid fan, who may not be able to maintain a proper distance from the object of his fandom, and that of the mass tourist, who without thinking simply follows the herd.

\section{Conclusion}

Film director Woody Allen seemed for a long time to be an inveterate New Yorker. Classics like Annie Hall (1977), Manhattan (1979), Radio Days (1987) and New York Stories (1989), each took place in the streets of Manhattan. A decade ago Woody Allen decided, mainly for financial reasons, to go in a different direction. He approached European capitals with the offer of shooting a new feature film in their city, with one condition: a large part of the production costs were to be borne by the city. This financial arrangement produced within a few years a successful series of blockbusters: Match Point (2005), Vicki Christina Barcelona (2008), Midnight in Paris (2011) and To Rome with Love (2012). Not only were the city names included in the titles of most of the films, there was also an assurance that the tourist highlights of the cities mentioned were frequently in shot. Thus, Midnight in Paris took place in locations like Montmartre, the Île de la Cité, and against the background of the Sacre Coeur. Audiences did not seem to be too bothered by this disguised form of city marketing: Midnight in Paris was Allen's most successful film ever.

Woody Allen's cinematographic/tourist trip through Europe is a vivid example of the ongoing fusion between the media industry and the tourism sector, and the increasing awareness of this among directors, producers, city marketeers and tourism businesses. Despite this strong interest, however, little is known about the underlying logic: what ultimately do movies, TV series, books and other media products contribute to the image of a city, and under what circumstances do these acts of image-making actually result in new tourism flows? Existing knowledge about these questions is very fragmented and unrepresentative, because it is mainly based on separate case studies of a limited number of eye-catching, successful works of art (Connell, 2012, p. 1012).

This article has attempted to go beyond the limited scope of individual case studies and to explore an underlying, more generic process. It investigates which stories are remembered by individuals, the role of place in this memory and under what circumstances people decide whether or not to go travelling to the existing locations associated with these stories. With that goal in mind, indepth interviews were conducted with fifteen respondents. Although fifteen is a limited number and the respondents certainly do not form a representative sample of the global population, some tentative conclusions may, with care, be drawn from these interviews. 
Firstly, the interviews show that every human being has a small treasure trove of stories which they love: movies, novels or TV series which people got to know in childhood or more recently and which are very important to them. The memory of these stories is incomplete and clouded: names and parts of the plot are partly forgotten, and in some cases, there is no more than one association. In the context of everyday life, the memory of these stories only rarely floats to the surface, triggered by external stimuli - such as certain smells, images or spaces - or from the inside by the semi-automatic and associative thought processes of daydreams. These sporadic memories, however, are considered as valuable and intriguing. This finding confirms earlier research into the importance of stories in daily life, but at the same time also puts its importance into perspective.

Secondly, there seems to be in the memory of beloved stories a significant role reserved for the physical spaces in which these stories are played out. The diegetic world forms, alongside plot and character, an important tool for recalling, extending and experiencing the memory. What is particularly remarkable is the fact that back in these memories the same areas reoccur. Each respondent appears to have a preference for a specific landscape ideal type, such as the forest, the village or the mountains. It was concluded that these patterns do not say as much about the textual characteristics of the stories, but about the way in which these stories are appropriated in the perception of the respondent. The symbolic environments in beloved stories are equated to people's own (youth) environment, or are interpreted as a symbol of how the respondents perceive their own identity.

Finally, the interviews suggested that there is a strong relationship between tourism and beloved stories. On the one hand books, TV series and films are often consumed which have their settings at the planned travel destinations, while vacation choices are partly based on existing associations derived from popular stories. In this sense, there is a latent basis for media tourism. Asked about the motivations and expectations of media tourism respondents gave four reasons: 1 ) the desire to step into the shoes of a character and become part of a beloved story, 2) to identify and pay respect to the underlying creative process of highly praised writers or directors, 3 ) identification with the values of a story and the hope that visiting their locations can support this attitude, 4) the desire to 'play' with their own memory and imagination, sometimes in the company of like-minded people. Some of these patterns have been identified in a small number of previous studies, but separately from each other. This article is the first to offer a more coherent and detailed description of motivations to visit media-related locations, contextualized within a long-term decision-making process.

Besides these tentative conclusions a couple of questions have been raised which cannot be answered within the scope and purpose of this study, but nevertheless deserve some follow-up. What, for example, was noticeable during the interviews was that the choice of particular symbolic 
environments seems to be related to gender. Two or five of the female respondents, for example, mentioned 'the house' while among male respondents 'hilly landscapes' appear to be popular. However, the number of respondents is too low to draw convincing conclusions. More generally, more attention needs to be paid to the question of how the memory of beloved stories can vary depending on the social-cultural background of the individual.

In addition, in this research, all the stories were approached generically without considering the specific media environment in which the stories were told. It is questionable whether audiovisual stories (films and television series) are appropriated in a similar way to text-based stories (literature). The imagination required while reading seems to differ substantially from the viewing experience of films and television. It is also plausible to suppose that, within one medium, different genres excite the desire to travel in different ways (cf. Laing \& Crouch, 2009; Laing \& Frost, 2012). Comparative research remains to be done in this regard, as does more fundamental research into the process of imagination.

This last question remains for the time being the most pressing. For despite the fact that everyone has an imagination and that it is the imagination that seems to distinguish us from other life forms, scientific knowledge about this phenomenon seems to be markedly limited. The study of media tourism - to which this article has made a contribution - is one but certainly not the only starting point for bridging this gap in the future. 


\section{References}

Adams, J.D. (2014). Embodied travel. In search of the Caribbean self in tropical places and spaces. In G. Lean, R. Staiff \& E. Waterton (Eds.), Travel and imagination (pp. 25-38). Farnham: Ashgate.

Appadurai, A. (1996). Modernity at large. Cultural dimensions of globalization. Minnesota: University of Minnesota Press.

Bal, M. (1994). Narrotology. Introduction to the theory of narrative. Toronto: University of Toronto Press.

Beeton, S. (2005). Film-induced tourism. Bristol: Channel View Publications.

Berger, A.A. (1997). Narratives in popular culture, media, and everyday life. London etc.: Sage Publications.

Bryman, A. (2004). Social research methods. Oxford: Oxford University Press.

Buchmann, A. (2006). From Erewhon to Edoras: tourism and myths in New Zealand. Tourism Culture and Communication, 6(3), 181-189.

Buchmann, A., Moore, K. \& Fisher, D. Experiencing film tourism: authenticity and fellowship. Annals of Tourism Research, 37(10), 229-248.

Butler, R.W. (1990). The influence of the media in shaping international tourist patterns. Tourism Recreation Research, 15(2), 46-53.

Caughey, J.L. (1984). Imaginary social worlds. A cultural approach. Lincoln (NB): University of Nebraska Press.

Cohen, J. (1986). Promotion of overseas tourism through media fiction. In J. Bendy (Ed.), Tourism Services Marketing: Advances in Theory and Practice. Proceedings of the Special Conference on Tourism Services Marketing (pp. 229-237). Cleveland, OH: Academy of Marketing Science.

Connell, J. (2012). Film tourism. Evolution, progress and prospects. Tourism Management, 33, 10071029.

Crough, D., Jackson, R. \& Thompson, F. (2005). The media and the tourist imagination: converging cultures. London: Routledge.

Ehn, B. \& Löfgren, O. (2010). The secret world of doing nothing. Berkely: University of California Press.

Frost, W. (2006). Braveheart-ed Ned Kelly: historic films, heritage tourism and destination image. Tourism Management, 27(2), 247-254.

Frost, W. (2010). Life changing experiences: film and tourists in the Australian outback. Annals of Tourism Research, 37(3), 707-726.

Goffman, E. (1959). The presentation of self in everyday life. Garden City: Doubleday.

Gottschall, J. (2013). The storytelling animal. How stories make us human. Boston: Mariner Books. 
Jones, D. \& Smith, K. (2005). Middle-earth meets New Zealand: authenticity and location in the making of The Lord of the Rings. Journal of Management Studies, 42(5), 923-945.

Kim, S. S. (2010). Extraordinary experience: re-enacting and photographing at screen tourism locations. Tourism and Hospitality Planning \& Development, 7(1), 59-75.

Kim, S.S. (2012). Audience involvement and film tourism experiences: emotional places, emotional experiences. Tourism Management, 33(2), 387-396.

Laing, J. \& Crouch, G.I. (2009). Exploring the role of the media in shaping motivations behind frontier travel experiences. Tourism Analysis, 14, 187-198.

Laing, J. \& Frost, W. (2012). Books and travel. Inspiration, quests and transformation. Bristol: Channel View Publications.

Lean, G., Staiff, R. \& Waterton, E. (2014). Reimaging travel and imagination. In G. Lean, R. Staiff \& E. Waterton (Eds.) Travel and imagination, pp. 9-24. Farnham: Ashgate.

Lukinbeal, C. \& A. Fletchall (2014). The hollowed or hallowed ground of Orange County, California. In J. Lester \& C. Scarles (Eds.) Mediating the tourist experience, pp. 223-236. Farnham: Ashgate.

Macionis, N. (2004). Understanding the film-induced tourist. In W. Frost, W. G. Croy \& S. Beeton (Eds.) Proceedings of the international tourism and media conference, pp. 86-97. Melbourne: Tourism Research Unit, Monash University.

Reijnders, S. (2011). Places of the imagination. Media, tourism, culture. Farnham: Ashgate Publishing. Riley, R. \& Van Doren, C.S. (1992). Movies as tourism promotion: a 'pull' factor in a 'push' location. Tourism Management, 13(3), 267-274.

Riley, R., Baker, D. \& Van Doren, C.S. (1998). Movie induced tourism. Annals of Tourism Research, 25(4), 919-935.

Riley, R.B. (1992). Attachment to the ordinary landscape. In I. Altman \& S.M. Low (Eds.), Place attachment (pp. 13-35). New York: Plenum Press.

Roesch, S. (2009). The experiences of film location tourists. Bristol: Channel View Publications.

Seaton, A.V. (2002). Tourism as metempsychosis and metensomatosis. The personae of eternal recurrence. In G. Dann (Ed.), The tourist as a metaphor of the social world (pp. 135-168). Wallingford: $C A B I$.

Torchin, L. (2002). Location, location, location. The destination of the Manhattan TV tour. Tourist Studies, 2(3), 247-266.

Tuan, Y. (1974). Topophilia. A study of environmental perception, attitudes, and values. New Jersey: Prentice Hall.

Tzanelli, R. (2004). Constructing the 'cinematic tourist'. The 'sign industry' of The Lord of the Rings. Tourist Studies, 4(1), 21-42.

Urry, J. \& Larsen, J. (2011). The tourist gaze 3.0. London: Sage. 